\title{
Innovación frugal y disruptiva
}

\author{
Frugal and disruptive innovation
}

\author{
Cristian Muñiz ${ }^{1}$
}

E xiste una máxima en la Anestesiología que aprendemos tempranamente en nuestra formación: "Si algo no se puede arreglar con tela adhesiva, no tiene arreglo". Esta frase resume una característica muy frecuente en los anestesiólogos, que es la capacidad de resolver problemas usando un mínimo de materiales, mucho ingenio y creatividad.

Para quienes de niños, crecieron viendo "Los Magníficos" y "MacGyver" en la televisión, el buscar soluciones a los problemas usando y adaptando lo que fuera que esté al alcance, es algo intuitivo. Incluso, el concepto "MacGyvering" puede encontrarse en la literatura científica para describir la acción de dar soluciones a problemas clínicos, usando ingenio y elementos básicos como la tela adhesiva.

Todos quienes hayan incurrido en esta práctica, de cierta forma se han acercado (tal vez sin saberlo) al concepto de "innovación frugal", que consiste en el desarrollo de herramientas científicas a costos mínimos y al alcance de cualquier persona.

El mejor ejemplo de un innovador en "Ciencias Frugales" es tal vez el profesor Manu Prakash (jefe del laboratorio de Ciencias Frugales de la Universidad de Stanford, el "Prakash Lab").

El Dr. Prakash detectó que una causa importante de muertes en África, es la malaria, una enfermedad infecciosa causada por plasmodios (los asociados a enfermedad suelen ser el $P$. falciparum, el $P$. vivax, el $P$. ovale y el $P$. malariae). Para diagnosticar esta enfermedad, el examen clásico es el análisis de "gota gruesa", el cual, al ser un examen por microscopía, requiere por definición de un microscopio.

El profesor Prakash observó que un problema de salud pública era la carencia de microscopios en la abundancia suficiente como para afrontar el inmenso número de casos que requieren de este examen para su diagnóstico. Los microscopios (si bien ajenos a nuestra práctica anestésica, son viejos conocidos de nuestros años universitarios cuando pasamos por histología y por microbiología), son equipos muy caros, pesados, aparatosos y difíciles de mantener, por lo que no están pensados para llevarlos a terreno en lugares como África.

En respuesta a este problema, el profesor Prakash diseñó el "Foldscope", un microscopio "origami", que consiste en una hoja de papel, que contiene una pequeña bolita de cristal y un circuito integrado a una luz led. Al doblar y plegar, esta hoja se convierte en un microscopio que cabe en la palma de la mano y que cuesta alrededor de 50 centavos de dólar (Figura 1).

Otro concepto relacionado a la "innovación frugal" y que tal vez se nos hace más familiar como anestesiólogos, es la "innovación disruptiva", que consiste en aquellas innovaciones que como su nombre dice, irrumpen en un medio y establecen un nuevo estándar, generando un cambio drástico que puede incluso llevar a la desaparición a otras tecnologías o técnicas previas que constituían el estándar.

Probablemente, el mejor ejemplo que podemos encontrar en la anestesiología es la "máscara laríngea", décimo tercera patente de invención del Dr. Archie Brain.

Creada en 1981, a partir de elementos clínicos reciclados y de un ingenio extraordinario, es probablemente el ejemplo más puro de la invención desde la

Médico Anestesiólogo, Residente de UPC de la Clínica de la Universidad de los Andes.

Inventor - Fundador de SIOL.

Fecha de ingreso: 21 de septiembre de 2020

Fecha de aceptación: 05 de octubre de 2020

\section{ORCID}

https://orcid.org/0000-0003-4426-6794

Correspondencia:

cristiancmh@gmail.com 


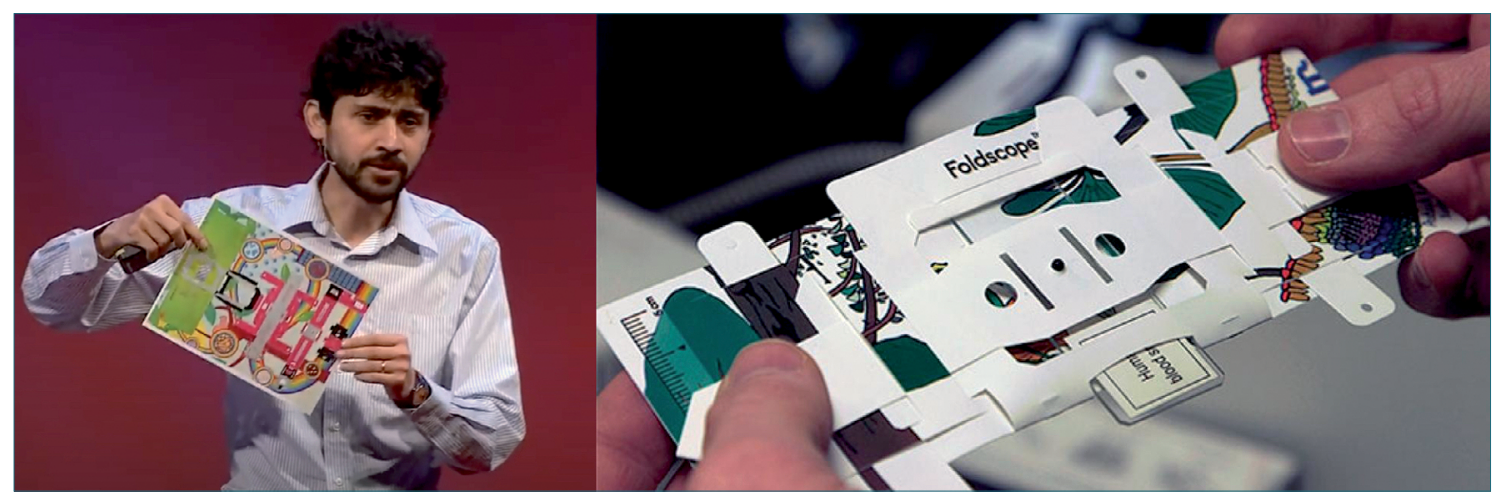

Figura 1. A la izquierda, el profesor Manu Prakash durante una charla TED. A la derecha, el "Foldscope" plegado.

comprensión absoluta de un problema. Solo alguien que haya sentido correr ese sudor frío por la espalda cuando se tiene un paciente cianótico y desaturando en la mesa quirúrgica, al que resulta imposible intubar o ventilar, podría haber ideado una solución tan potente y extraordinaria como la LMA.

Irónicamente, en un principio, la empresa Teleflex rechazó la LMA como producto por no creer que tuviera futuro (jvaya error!), lo que deja en evidencia lo difícil que es innovar aun cuando una idea sea extraordinaria (Figuras 2 y 3 ).

El ejemplo del Dr. Brain, nos demuestra que todo invento proviene primero y fundamentalmente, de la existencia de un problema. Dicho problema puede ser simple o complejo, pero el primer paso es identificar que dicho problema existe y comprenderlo lo mejor posible.

Otro ejemplo de innovación disruptiva que nos es cercano, es la "técnica de Seldinger", desarrollada por el Dr. Sven Ivar Seldinger (radiólogo intervencional), quien ideó el genial método de conducir un catéter usando una guía metálica e intercambiando agujas, dilatadores y catéteres en forma secuencial, condenando a la desaparición la denudación quirúrgica como técnica estándar. Hoy es difícil imaginar

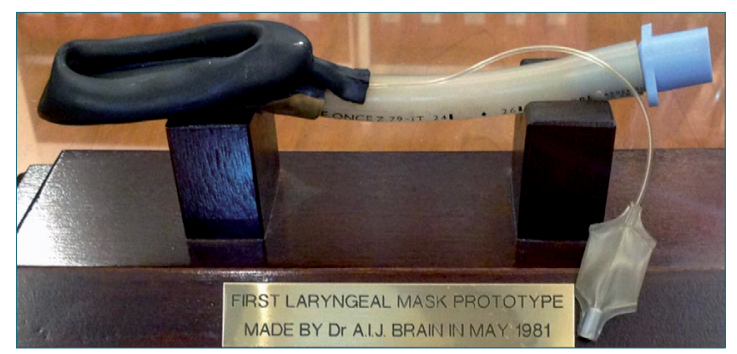

Figura 2. El primer prototipo de la LMA. otra forma mejor de instalar un catéter, prueba de lo sencillamente genial de su idea.

En la antigüedad, todos los instrumentos y dispositivos médicos, provenían de necesidades puntuales de los propios médicos y de sus propias ideas y diseños conceptuales, los que eran luego muchas veces entregados a maestros fabricantes de instrumentos como Joseph Frédéric Benoît Charrière (de nacionalidad francesa y de quien proviene la famosa unidad "French"), quienes construían estos instrumentos según las instrucciones de los propios médicos.

Es así como muchos de los insumos e instrumen-

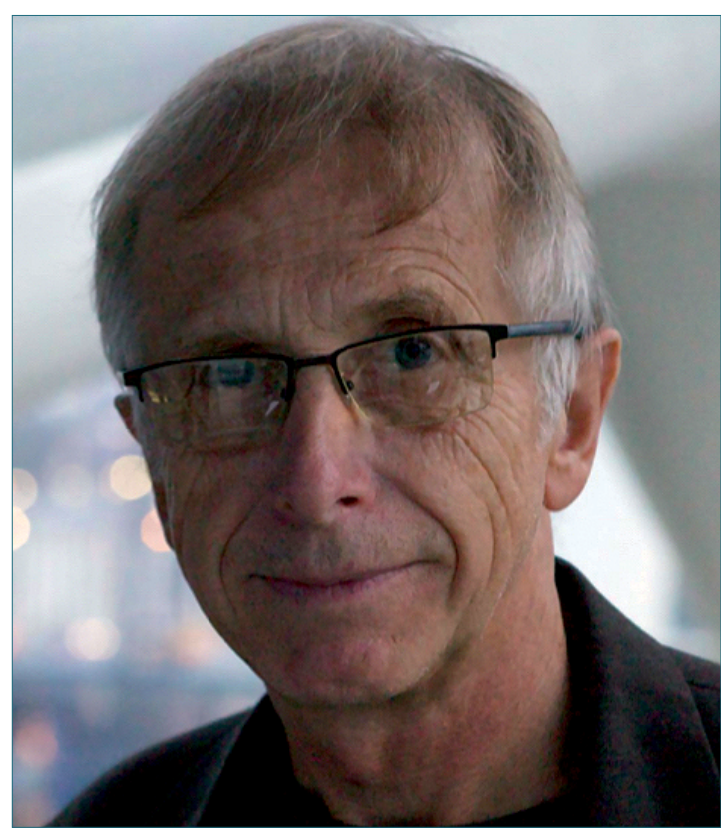

Figura 3. Dr. Archie Brain. 
tos que hoy utilizamos, poseen nombres propios, en honor a sus creadores, tales como la cánula de Guedel, creada por el Dr. Arthur E. Guedel, la sonda Foley, creada por el Dr. Frederic Eugene Basil Foley, los Drs. William Ganz y Jeremy Swan, quienes co-inventaron el catéter de arteria pulmonar, etc. La lista de médicos inventores es tan inmensa que sería casi imposible citarlos a todos.

Desafortunadamente, con el tiempo, los médicos hemos ido dejando de lado esta creatividad y descansando esta labor en los ingenieros y en la industria de los dispositivos médicos, quienes han creado un enorme mercado en torno a solucionar problemas clínicos.

El problema de este modelo que hoy es el que impera, es que para obtener un dispositivo o una solución, es necesario que los ingenieros que los diseñan, primero conozcan de la existencia de un problema o necesidad que ellos mismos no viven y, segundo, que logren comprender verdaderamente la esencia de dicho problema.

Este proceso de conocer y entender es tanto más difícil para quienes no viven el problema mismo, que muchas veces resulta en la creación de sofisticadas soluciones, a veces más complejas de lo necesario y no siempre todo lo practicas que pudieran ser (razón muchas veces, además, de que los dispositivos tengan costos prohibitivos para la gran mayoría de nuestros pacientes).

Si uno desea dar solución a un problema que lo aqueja, y desea hacerlo con una solución tan radicalmente genial como las que hemos citado, esa idea debe provenir idealmente de uno mismo.

Desafortunadamente, el camino de la innovación no es fácil, ni rápida, ni barata. Desarrollar una idea desde su concepción hasta su escalamiento a nivel industrial, tiene muchas etapas, cada una con sus propias dificultades.

La primera gran barrera que enfrenta un innovador o inventor, es la de creer en su idea y conservar esa seguridad frente a las críticas de sus pares. Es habitual encontrarnos con colegas que desmerecen una solución por sentirse "por sobre" el problema a solucionar, o bien un jefe que, en lugar de darnos un espacio para desarrollar un nuevo proyecto, hace todo lo contrario. Razones existen muchas, desde los celos hasta la indiferencia y tantas más que hacen que a veces, los innovadores puedan ser incluso objeto de burlas y bromas. Un buen ejemplo podría ser una innovación reciente que consistió en adaptar máscaras de buceo deportivo para utilizarlas como respiradores de cara completa, adaptándoles filtros bacteriano/ virales. Si bien esta idea se adoptó en mas de 150 países durante la actual pandemia del COVID-19, en Chile a algunos les pareció chistosa y hubo quienes incluso acuñaron nombres como "el invento del hombre rana". Sin embargo, recordemos el ejemplo del Dr. Brain, muchas veces, la falta de visión, celos u otras razones, hacen que aparezcan detractores a las ideas a lo largo del camino, pero tal y como lo hizo el Dr. Brain, lo que hay que hacer es avanzar con fe y convicción ("Si parece ridículo pero funciona, no es ridículo") (Figuras 4 y 5).

Sin embargo, una vez que se tiene una idea en la que se cree firmemente, lo que sigue es protegerla. Desafortunadamente, para proteger una idea, a través de una patente, es necesario un largo y tedioso

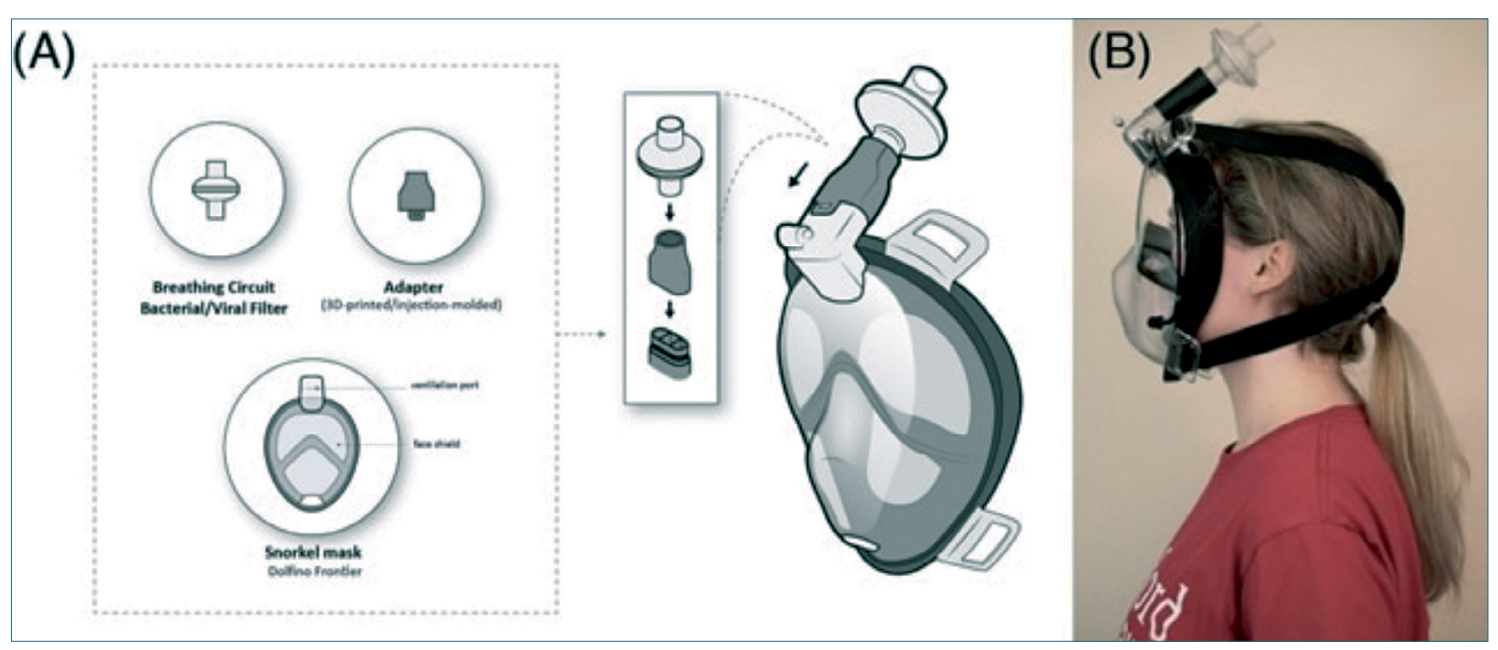

Figura 4. El diagrama de la "Pneumask", adaptación de máscara de snorkel como EPP de la Universidad de Stanford. 


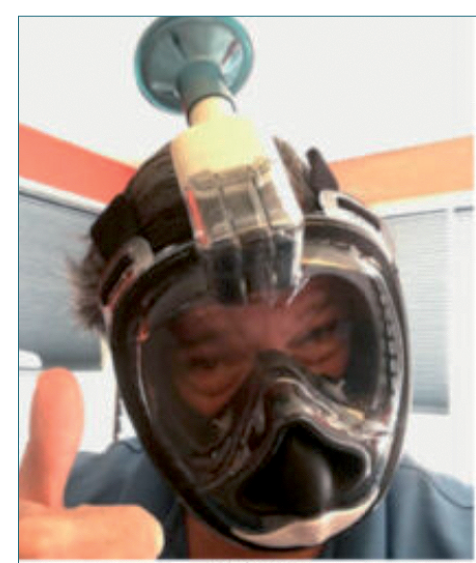

NY, USA

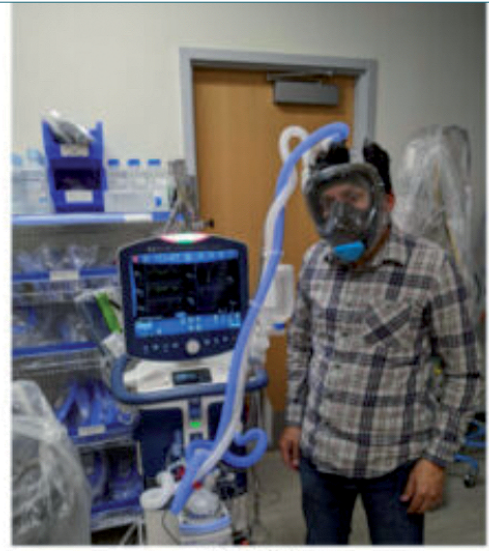

UT, USA

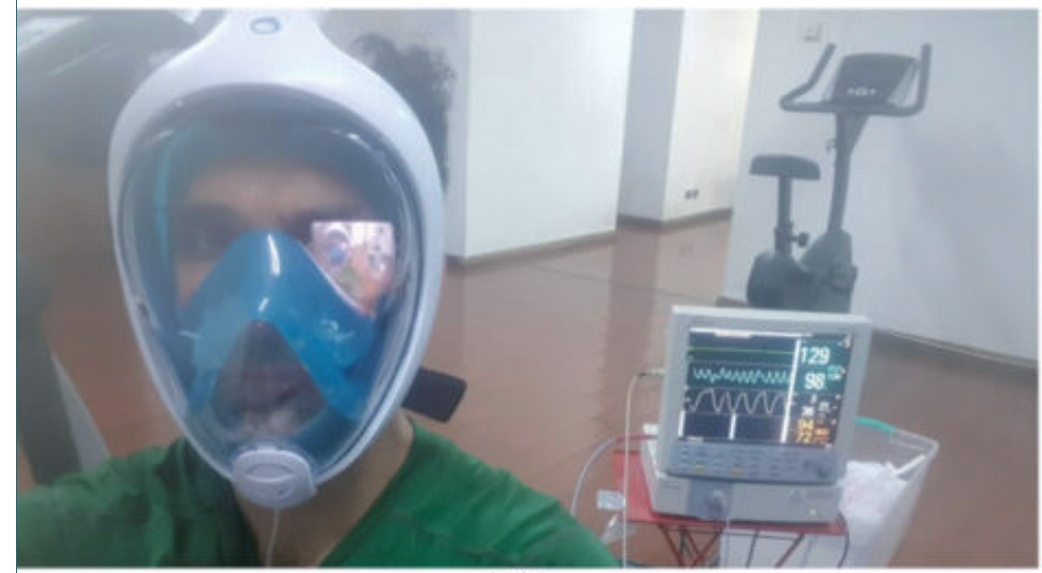

Chile

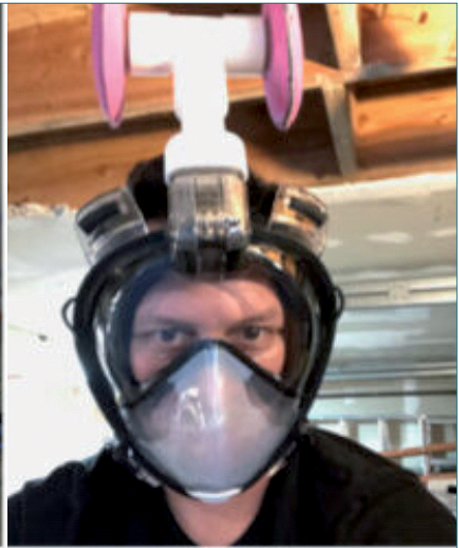

CA, USA

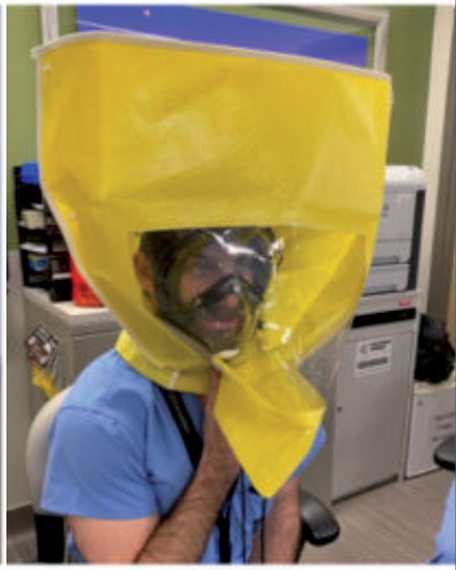

UT, USA

Figura 5. Diferentes configuraciones y pruebas de la Pneumask por diferentes miembros del equipo desarrollador.

proceso, con aspectos muy técnicos, que puede durar incluso años y que suele ser tremendamente costoso.

Es así como muchas ideas terminan en lo que en innovación se conoce como "el Valle de la Muerte", aun cuando sean excelentes ideas (Figura 6).

Es en esta etapa inicial en que habitualmente el innovador se sustenta en recursos propios o recurre a "las 3 F" (Friends, Family and Fools).

Un camino alternativo es postular a fondos o capitales de los que existen diversos tipos, desde capitales como CORFO, hasta redes de inversiones, incubadoras de negocios, capitales ángeles, etc.

Es aquí donde se debe decidir hasta qué punto se cede el control y la propiedad de una idea a manos de terceros con el objeto de lograr que esta se materialice.

El riesgo de ceder el dominio de una idea, es que quienes se convierten en "socios" al aportar el capital

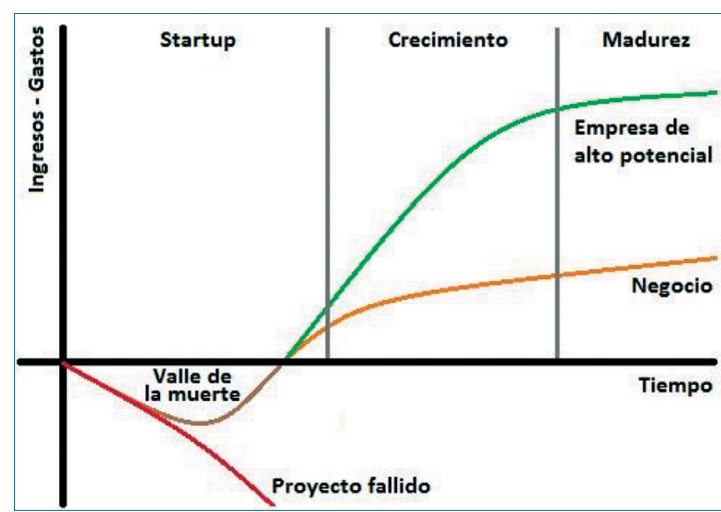

Figura 6. Curva clásica de la evolución de un proyecto en innovación. 


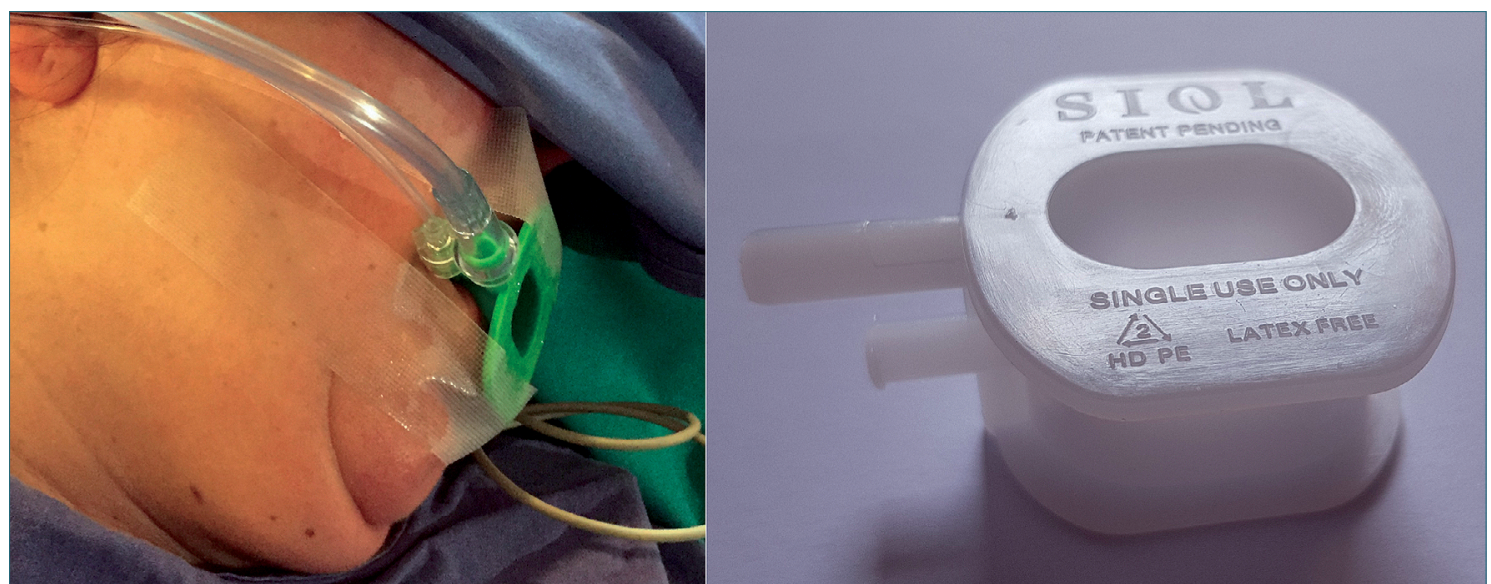

Figura 7. A la izquierda, el primer prototipo de la "Boquilla $\mathrm{M}_{1}$ " de "Siol", en impresión 3D, en el primer caso con paciente. A la derecha, la primera versión de la "Boquilla $\mathrm{M}_{1}$ " de "Siol", en inyección plástica de grado industrial en HDPE, hecha en Chile.

no compartan los principios o la visión originales desde donde nació la idea originalmente.

Pese a estas dificultades, es posible sacar adelante proyectos. Los caminos son variados.

Un camino es emprender por cuenta propia con recursos propios y apostar al éxito a largo plazo. Un ejemplo de esto es la "boquilla $\mathrm{M}_{1}$ ", una boquilla para endoscopía que administra oxígeno y permite medir $\mathrm{CO}_{2}$, todo en 1 sola pieza, que busca conciliar la solicitud de los endoscopistas de un campo de trabajo despejado, con nuestro eterno interés como anestesiólogos de tener un paciente bien oxigenado y monitorizar su ventilación (Figura 7).

Este invento busca ser una "solución frugal" al haber sido diseñado para ser de bajo costo y accesible para cualquier paciente.

Sin embargo, existen también proyectos que ofrecen dificultades técnicas además de económicas, que hacen necesario desarrollarlos en conjunto con capitales de inversión.

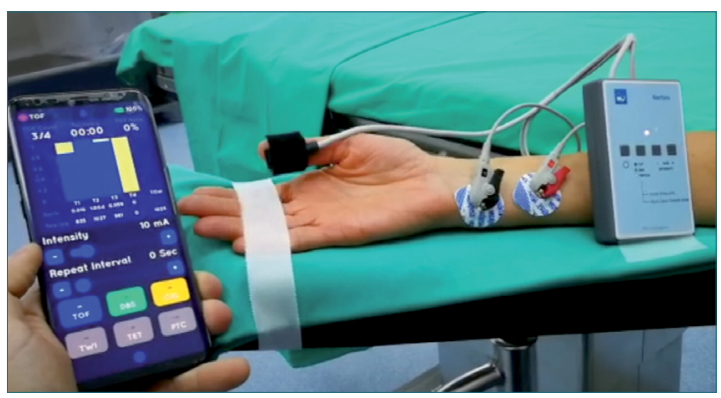

Figura 8. El primer prototipo de "iTOF" de "Nerbio", siendo usado en paciente real.
Un ejemplo de esto, es "iTOF", un estimulador de nervio periférico para medir tren de cuatro, de bajo costo e inalámbrico (Figuras 8 y 9).

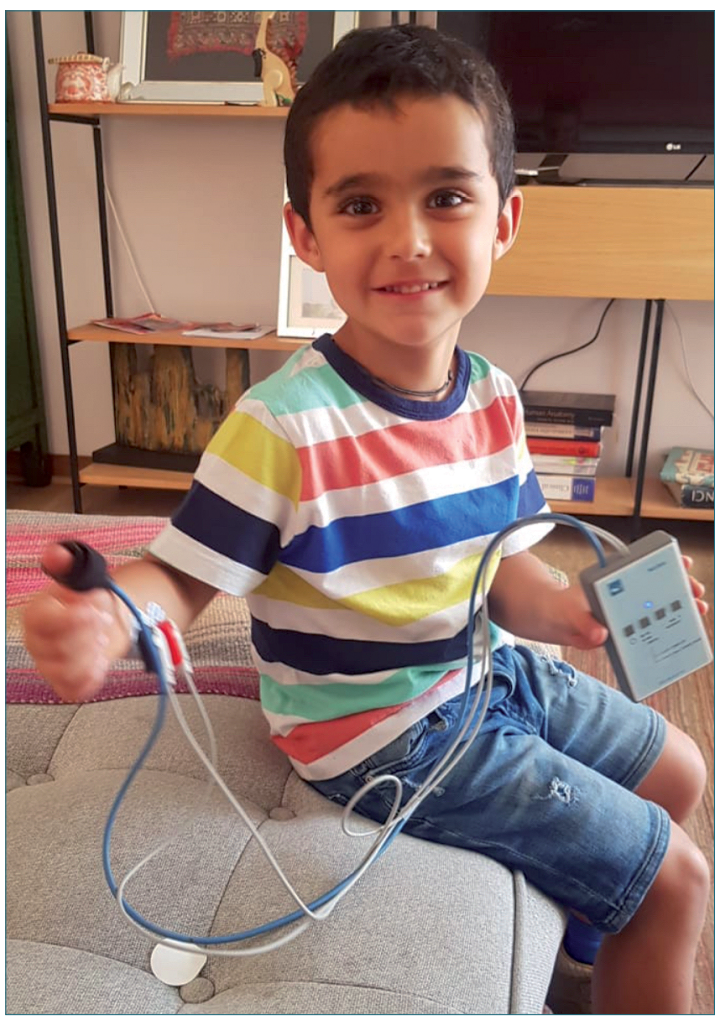

Figura 9. Primer prototipo de "iTOF" de "Nerbio" en Chile, durante su etapa de desarrollo. 
Este dispositivo que se controla através de un Smartphone conectado por Bluetooth y que tiene todas las modalidades del TOF más sofisticado del mercado (y más inclusive), pero que en lugar de costar 3.000 a 5.000 dólares, vale alrededor de 200 dólares, una pequeña fracción de lo que cuesta un TOF hoy.

Probablemente, una de las últimas barreras y probablemente una de las más difíciles, corres-ponde a las certificaciones. Hoy vivimos una suerte de "fiebre de las certificaciones", donde los comités de calidad $y$ de infecciones intrahospitalarias, se tornan en duros obstáculos. Pese a esto, nuestra responsabilidad como médicos y como científicos es retornar a la tra- dición antigua de buscar soluciones a los problemas clínicos, soluciones que provengan desde la vivencia y el conocimiento íntimo de los problemas y soluciones dirigidas principalmente a nuestros pacientes y que estén al alcance de todos ellos, sin que el costo sea un impedimento. "Una solución que no está al alcance de todos, no es una verdadera solución".

Esto no es un imposible, ya hay ejemplos incluso en Chile, de que con voluntad, convicción y perseverancia, es posible lograr este objetivo, solo resta que todos tengamos una mentalidad abierta hacia los innovadores y que impulsemos y potenciemos a nuestros "MacGyvers". 